\title{
Neural lipoma in little finger with macrodactyly
}

\author{
Vishal Mago ${ }^{1 *}$ and Neetu Kochhar ${ }^{2}$ \\ ${ }^{1}$ Associate Professor, Department of Plastic Surgery, Bhagat Phool Singh Government Medical College for Women, Khanpur kalan, Sonepat, Haryana, India \\ ${ }^{2}$ Associate Professor, Department of Obstetrics and gynecology, Bhagat Phool Singh Government Medical College for Women, Khanpur kalan, Sonepat, Haryana, \\ India
}

\begin{abstract}
Neural lipoma is a rare benign tumour commonly involving the median nerve and other less frequently involved nerves include the ulnar, radial, brachial plexus, superficial peroneal nerve, inferior calcaneal nerve and median plantar nerve. This report describes the rare occurrence of neural lipoma in the digital nerve of little finger associated with digital gigantism of right little finger and ulnar border right hand with no associated motor or sensory deficits.
\end{abstract}

\section{Introduction}

Neural fibrolipoma is a benign neoplasm of nerves, resulting from anomalous growth of fibro adipose tissue of the nerve sheath. Mason y described neural fibrolipoma of hand for the first time in 1953. It affected the median nerve most commonly, with a slow-growing tumor at the volar aspect of the wrist, with features of compressive neuropathy. This tumor can affect other nerves like the ulnar nerve, radial nerve, and brachial plexus to a lesser extent. Neural fibrolipoma is associated with macrodactyly in $27-67 \%$ cases [1-3]. This entity usually involves the second and third digits of the hand or foot, but multiple digits may be affected. Isolated cases of neural fibrolipoma have been reported in the head and neck region.

Digital macrodactyly is an unusual congenital anomaly that is present at birth and is progressive during the period of normal skeletal growth. There are three variants of this unusual anomaly [4,5]. They are type I digital gigantism with lipofibromatous hamartoma of a peripheral nerve, type II digital gigantism associated with neurofibromatosis, and type III hyperostotic digital gigantism. In the adult, arthrodesis of the interphalangeal joints with bony shortening or ray resection may be indicated. The association of neural lipoma with macrodactyly is rarely described in the literature. This is a rare case seen in our plastic surgery department of a isolated case of neural lipoma with type 1 macrodactyly.

\section{Case report}

A 12-year-old girl was brought to the plastic surgery department with complaints of increasing size of little fingers of right hand and swelling over ulnar border of right hand since birth (Figure 1). There was no history of any other deformity or illness associated with the hand deformity. Developmental milestones achieved were appropriate for age. On local examination, macrodactyly of little finger of right hand (type 1), was noted along with palpable soft tissue mass over the ulnar aspect of right palm. There was no associated tenderness, sensory loss or vascular changes. General physical examination and routine laboratory parameters were normal. Amputation of the enlarged right little finger with debulking was performed (Figure 2).

Grossly the cut surface had a homogenous fatty appearance. The subcutaneous tissue resected along with the lesion was infiltrated by the tumour. Microscopical examination revealed an uncircumscribed lipomatous tumour surrounding the nerve fascicles. The tumour comprised of mature adipose tissue and fibrous tissue entrapping the nerve fibres and infiltrating the epineurium of the nerve. It was accompanied by perineural fibrosis. The surrounding subcutaneous area was involved by the tumour. There was no neural hypertrophy or inflammation. A histological diagnosis of neurolipoma was made. Post-operative recovery was uneventful.

\section{Discussion}

Peripheral nerve tumours account for $<5 \%$ of all tumours of the hand. The most common peripheral nerve tumours of the hand are schwannomas (neurilemmomas) and neurofibromas. Neural

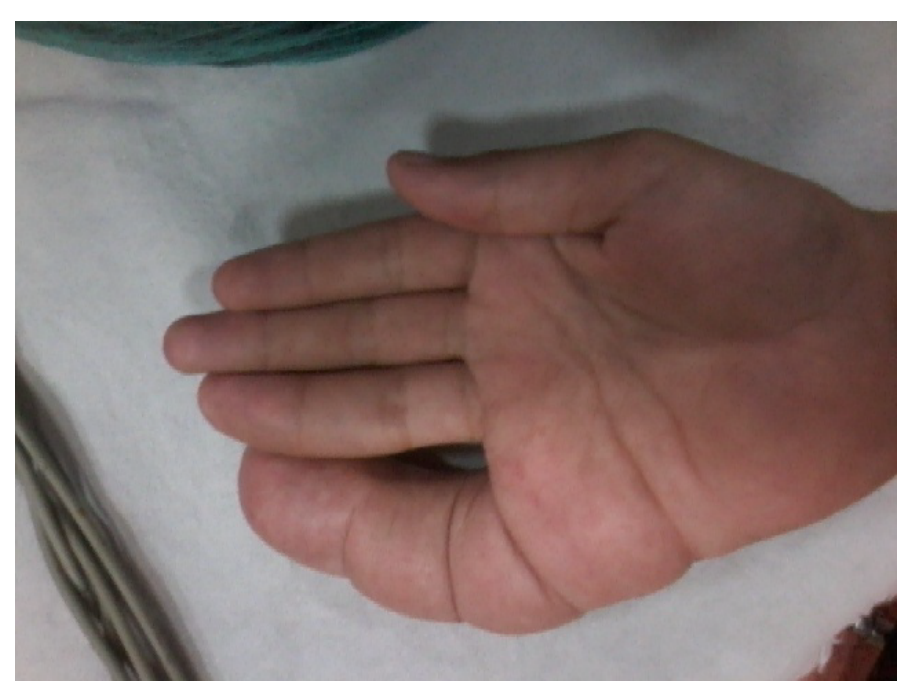

Figure 1. Type 1 macrodactyly involving little finger extending volar aspect right hand.

Correspondence to: Vishal Mago, Associate Professor, Department of Plastic Surgery, Bhagat Phool Singh Government Medical College for Women, Khanpur kalan, Sonepat, Haryana, India, E-mail: drvishalm@yahoo.com

Received: June 01, 2017; Accepted: June 20, 2017; Published: June 23, 2017 


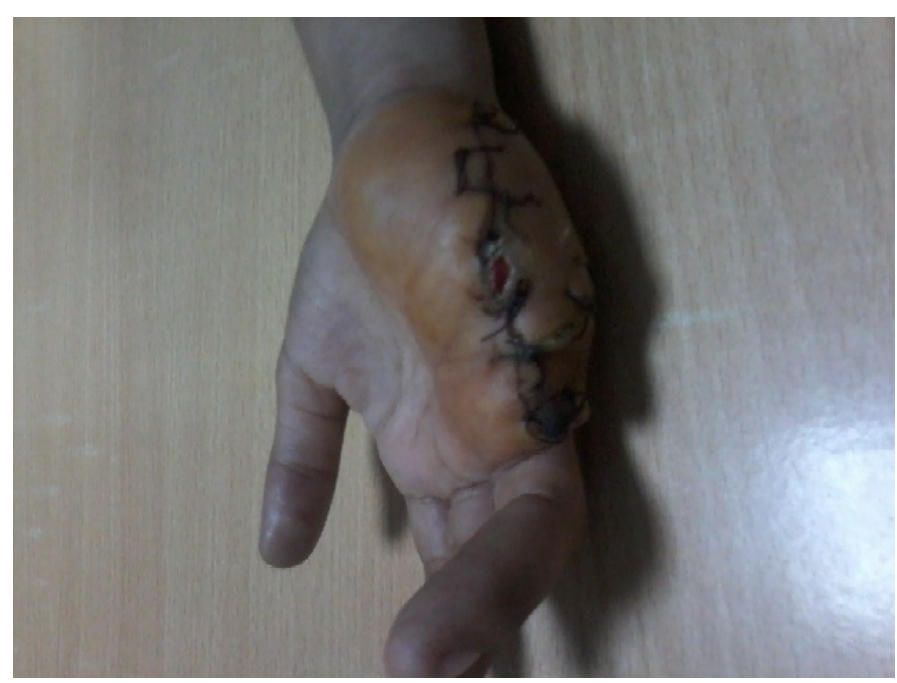

Figure 2. Postoperative result.

fibrolipoma or lipofibromatous hamartoma of the nerve is a rare benign tumour of unknown origin. The median nerve is most commonly involved, but involvement of other nerves has been reported. It is rarely found in the digital nerves at the peripheral level [6-8].

Jung, Yim and Kwon reported a rare case of benign lipofibromatous hamartoma affecting the digital nerves in both hands. The shape of the hand improved only with partial excision similar to our case [9].

Silverman and Enzinger reported 26 cases where macrodactyly was associated in one third of patients with median nerve involvement [3].

Gupta A and others have reported a case of multiple neural fibrolipomas in a child with macrodactyly of both hands [7].
Major clinical features of neural fibrolipomas are gigantism of a digit, hands or feet since birth. JA Plaza and others reported 13 cases of fibrolipomatous hamartoma with unilateral lesions on the thenar areas, fingers, or both.

Diagnostic evaluation of macrodactyly is necessary, to rule out underlying cause such as fibrolipomatous hamartoma of a nerve, which if corrected early by surgical excision may prevent long-term disability. Neural fibrolipoma with macrodactyly is a rare lesion whose clinical presentation can range from a small lesion to a large mass involving the entire extremity.

\section{References}

1. Baviskar BP, Yashidkar, Dongre SP (2013) A rare case of neurolipoma. Int J Med Res Health Sci 2: 277-280.

2. Mason ML (1953) Proceedings of American society for surgery of the hand Presentation of cases. J Bone Joint Surg Am 35: 273-275.

3. Silverman TA, Enzinger FM (1985) Fibrolipomatous hamartoma of nerve. A clinicopathologic analysis of 26 cases. Am J Surg Pathol 9: 7-14. [Crossref]

4. Amadio PC, Reiman HM, Dobyns JH (1988) Lipofibromatous hamartoma of nerve. $J$ Hand Surg Am 13: 67-75. [Crossref]

5. Thornton MA, O'Leary G, Fitzgibbon J (2000) Neural fibrolipoma: an unusual case. $J$ Laryngol Otol 114: 231-232. [Crossref]

6. Taori K, Gyanchandani M, Rohatgi S, Ghonge N, Solanke R (2005) Cervico-mediastinal neural fibrolipoma: Spiral CT features. Indian J Radiol Imaging 15: 535-536.

7. Gupta A, Geetha V, Monappa V, Bhat SS (2011) Multiple neural fibrolipomas with macrodactyly. Indian J Dermatol 56: 766-767. [Crossref]

8. Plaza JA, Kazakov DV, Casas G, Requena L, Sanmartin O, et al. (2014) Fibrolipomatous hamartoma of the nerve: a clinicopathologic report of 13 cases. $J$ Am Acad Dermatol 70: 736-742. [Crossref]

9. Jung SN, Yim Y, Kwon H (2005) Symmetric lipofibromatous hamartoma affecting digital nerves. Yonsei Med J 46: 169-172. [Crossref]

Copyright: (C2017 Mago V. This is an open-access article distributed under the terms of the Creative Commons Attribution License, which permits unrestricted use, distribution, and reproduction in any medium, provided the original author and source are credited. 